\title{
Effectiviness of Low Dose Aripiprazole in the Treatment of an Adolescent Patient With Trichotillomania
}

\begin{abstract}
Necati Uzun
Elazığ Psychiatry Hospital, Elazığ, Turkey

\author{
Ömer Faruk Akça
}

Necmettin Erbakan University, Konya, Turkey

Trichotillomania (TTM) is an impulse control disorder characterized by the repetitive tearing of hair and eyebrows. TTM usually starts in adolescence. Some treatment modalities in the treatment of TTM, psychopharmacological therapies are one of the most commonly used methods, but treatment interventions, especially with serotonergic agents, do not always beneficial. It has been shown in several studies that second-generation antipsychotic agents, such as olanzapine, quetiapine, aripiprazole (ARP), risperidone may be useful as monotherapy or in combination in the treatment of trichotillomania. There is a limited number of data in the literature that using low dose ARP as monotherapy in the treatment of trichotillomania in adolescents. In this case report, we will present effectiveness of low dose aripiprazole monotherapy in the treatment of an adolescent girl with TTM.
\end{abstract}

Keywords: adolescent, trichotillomania, aripiprazole

\section{Introduction}

Trichotillomania (TTM) is an impulse control disorder characterized by the repetitive tearing of hair and eyebrows. TTM is a disorder that affects $3.4 \%$ of women and $1.5 \%$ of men, and usually starts in adolescence (Christenson, Pyle, \& Mitchell, 1991). Despite the presence of various methods in the treatment of TTM, psychopharmacological treatments are one of the most commonly used methods, but treatment interventions, especially with serotonergic agents, do not always produce good outcomes (Woods et al., 2006; Swedo et al., 1989; Christenson, Mackenzie, Mitchell, \& Callies, 1991). It has been shown in several studies that antipsychotic agents, such as olanzapine, quetiapine, aripiprazole (ARP), risperidone and pimozide may be useful as monotheraphy or in combination with serotonergic agents in the treatment of trichotillomania (Van Ameringen, Mancini, Patterson, Bennett, \& Oakman, 2010; Stein \& Hollander, 1992; Senturk \& Tanriverdi, 2002; Khouzam, Battista, \& Byers, 2002; White \& Koran, 2011). As far as we know there is limited number of data in the literature that using low dose ARP as monotheraphy in the treatment of trichotillomania in adolescent patients.

\section{Case Report}

The case presented here was a 15 year-old girl consulted our clinic with complaints of plucking her hair and eyebrows in repetative manner. She had been having this problem for about four years. In particular, she was plucking the frontal and occipital regions of her head. She described a slight itch in these areas before

\footnotetext{
Necati Uzun, consultant child and adolescent psychiatrist, Elazı ̆ Psychiatry Hospital.

Ömer Faruk Akça, associate professor, Department of Child and Adolescent Psychiatry, Meram School of Medicine, Necmettin Erbakan University.
} 
plucking her hair. According to her mother, she was plucking her hair alone in her own bedroom on her bed. After she plucked her hair, she store them in a bag. The patient was diagnosed as trichotillomania according to Diagnostic and Statistical Manual of Mental Disorders (5th ed.) (American Psychiatric Association, 2013). Clinical Global Index (CGI) score for trichotillomania was seven at the begining of treatment. Aripiprazole 2.5 $\mathrm{mg} /$ day was started and two weeks later trichotillomania symptoms improved slightly and CGI score was five at that visit. Aripiprazole doze was increased to $5 \mathrm{mg}$ /day and one month after the first admission, the patient's trichotillomania symptoms disappeared and had never recurred over four months of follow-up.

\section{Discussion}

Some of studies in adults reported that ARP reduces TTM symptoms (Jefferys \& Burrows, 2008; Virit, Selek, Savas, \& Kokaçya, 2009). TTM and obsessive-compulsive disorder symptoms of a 20 -year-old male patient is reported to benefit from ARP treatment even in low doses (1.5-3 mg/d) (Yasui-Furukori \& Kaneko, 2011). Likewise, a 14-year-old girl with TTM is reported to benefit from ARP in $1.5 \mathrm{mg} / \mathrm{d}$ dose (Sasaki \& Iyo, 2015). Similar to our case, these reports indicate that TTM symptoms may improve after admistrination of low dose ARP. In addition to these case reports, an open-label trial has reported that ARP may be effective in the treatment of TTM (White \& Koran, 2011). Arguing the neurobiological mechanism, ARP may be effective in the treatment of TTM by stabilizing dopamine in the prefrontal cortex accordingly improving motor inhibition deficits (Pae, Serretti, Patkar, \& Masand, 2008). Therefore, low dose ARP may be superior to high doses ARP in treating TTM symptoms. Further studies will improve our knowledge on this topic.

\section{References}

American Psychiatric Association. (2013). Diagnostic and statistical manual of mental disorders (5th ed.). Arlington, VA: American Psychiatric Publishing.

Christenson, G. A., Mackenzie, T. B., Mitchell, J. E., \& Callies, A. L. (1991). A placebo-controlled, double-blind crossover study of fluoxetine in trichotillomania. Am J Psychiatry, 148(11), 1566-1571.

Christenson, G. A., Pyle, R. L., \& Mitchell, J. E. (1991). Estimated lifetime prevalence of trichotillomania in college students. $J$ Clin Psychiatry, 52(10), 415-417.

Jefferys, D., \& Burrows, G. (2008). Reversal of trichotillomania with aripiprazole. Depress Anxiety, 25(6), 37-40.

Khouzam, H. R., Battista, M. A., \& Byers, P. E. (2002). An overview of trichotillomania and its response to treatment with quetiapine. Psychiatry, 65(3), 261-270.

Pae, C. U., Serretti, A., Patkar, A. A., \& Masand, P. S. (2008). Aripiprazole in the treatment of depressive and anxiety disorders: A review of current evidence. CNS Drugs, 22(5), 367-388.

Sasaki, T., \& Iyo, M. (2015). Treatment of puberty trichotillomania with low-dose aripiprazole. Annals of general psychiatry, 14: 18.

Senturk, V., \& Tanriverdi, N. (2002). Resistant trichotillomania and risperidone. Psychosomatics, 43(5), 429-430.

Stein, D. J., \& Hollander, E. (1992). Low-dose pimozide augmentation of serotonin reuptake blockers in the treatment of trichotillomania. J Clin Psychiatry, 53(4), 123-126.

Swedo, S. E., Leonard, H. L., Rapoport, J. L., Lenane, M. C., Goldberger, E. L., \& Cheslow, D. L. (1989). A double-blind comparison of clomipramine and desipramine in the treatment of trichotillomania (hair pulling). $N$ Engl J Med, 321, 497-501.

Van Ameringen, M., Mancini, C., Patterson, B., Bennett, M., \& Oakman, J. (2010). A randomized, double-blind, placebo-controlled trial of olanzapine in the treatment of trichotillomania. J Clin Psychiatry, 71(10), 1336-1343.

Virit, O., Selek, S., Savas, H. A., \& Kokaçya, H. (2009). Improvement of restless legs syndrome and trichotillomania with aripiprazole. J Clin Pharm Ther, 34(6), 723-725.

White, M. P., \& Koran, L. M. (2011). Open-label trial of aripiprazole in the treatment of trichotillomania. J Clin Psychopharmacol, 31(4), 503-506. 
Woods, D. W., Flessner, C. A., Franklin, M. E., Keuthen, N. J., Goodwin, R. D., Stein, D. J., \& Walther, M. R. (2006). Trichotillomania Learnig Center-Scientific Adviseoy Board. The Trichotillomania Impact Project (TIP): Exploring phenomenology, functional impairment, and treatment utilization. J Clin Psychiatry, 67(12), 1877-1888.

Yasui-Furukori, N., \& Kaneko, S. (2011). The efficacy of low-dose aripiprazole treatment for trichotillomania. Clin Neuropharmacol, 34(6), 258-259. 